\title{
Detection and location of the enzymes of de novo pyrimidine biosynthesis in mammalian spermatozoa
}

\author{
E. A. Carrey ${ }^{*}$, C. Dietz ${ }^{2}$, D. M. Glubb¹ , M. Löffler², \\ J. M. Lucocq ${ }^{3}$ and P. F. Watson ${ }^{4}$ \\ ${ }^{1}$ Department of Biochemistry and Molecular Biology, Royal Free and University College \\ Medical School, Royal Free Campus, London NW3 2PF, UK; ${ }^{2}$ Institut für Physiologische \\ Chemie, Philipps Universität Marburg, D-35033 Marburg, Germany; ${ }^{3}$ School of Life \\ Sciences, WTB/MSI Complex, University of Dundee, Dundee DD1 5EH, UK; and \\ ${ }^{4}$ Department of Veterinary Basic Sciences, Royal Veterinary College, London NW1 OTU, UK
}

Enzymes of the pathway for de novo biosynthesis of pyrimidine nucleotides have been reported in spermatozoa from fruitfly and mammals. The aim of the present study was to test the hypothesis that the enzymes for biosynthesis of uridine monophosphate (UMP) are concentrated near the mitochondria, which are segregated in the mid-piece of spermatozoa. Baby hamster kidney fibroblasts were compared with spermatozoa from rams, boars, bulls and men. Antibodies raised against synthetic peptides from sequences of the multienzyme polypeptides containing glutamine-dependent carbamyl phosphate synthetase, aspartate transcarbamylase and dihydroorotase (CAD) and UMP synthase, which catalyse reactions 1-3 and 5-6, respectively, were used, together with an affinity-purified antibody raised against dihydroorotate dehydrogenase (DHODH), the mitochondrial enzyme for step 4. Western blot analysis, immunofluorescent microscopy and immunoelectron microscopy confirmed that CAD and UMP synthase are found in the cytoplasm around and outside the mitochondria; DHODH is found exclusively inside the mitochondria. CAD was also located in the nucleus, where it has been reported in the nuclear matrix, and in the cytoplasm, apparently associated with the cytoskeleton. It is possible that CAD in the cytoplasm has a role unconnected with pyrimidine biosynthesis.

\section{Introduction}

All organisms have the capacity to synthesize nucleotides de novo and to salvage or recycle the components (bases or nucleosides); however, the balance between biosynthesis and recycling may differ in distinct types of cell and at crucial stages of development. In general, de novo biosynthesis is important in rapidly dividing cells in which there is an obvious requirement for new nucleic acids, and for uridine diphosphate (UDP)-sugars and cytidine diphosphate (CDP)-lipids that are used to make other components of cells.

The de novo pathway for the biosynthesis of the pyrimidine nucleotide uridine monophosphate (UMP) in all higher organisms involves six steps that in turn are found in only three polypeptides. The genetics of the pathway have been studied extensively in the fruitfly, Drosophila melanogaster. The proteins encoded by the Drosophila genes $r$, dhod and $r$-I are glutamine-dependent carbamyl phosphate synthetase, aspartate transcarbamylase and dihydroorotase (CAD; catalysing steps $1-3$ inclusive), dihydroorotate dehydrogenase $(\mathrm{DHODH}$; step 4$)$ and

*Correspondence address: Purine Research Unit, $5^{\text {th }}$ Floor, Thomas Guy House, Guy's Hospital, London Bridge, London SE1 9RT, UK Email: elizabeth.carrey@kcl.ac.uk uridine monophosphate synthase (UMPS; steps 5 and 6; comprising orotate phosphoribosyltransferase and orotidine 5' monophosphate (OMP) decarboxylase), respectively. Drosophila strains that are mutant in any of these genes have defective wings, and the females are sterile because they cannot provide the mRNA for the pyrimidinebiosynthetic enzyme in the embryos of their offspring. However, the immature and adult mutant fruitflies survive by synthesizing pyrimidine nucleotides from uracil and uridine obtained from the diet and from recycling, respectively (Nørby, 1970; Conner and Rawls, 1982).

Porter et al. (1995) and Yang et al. (1995) reported that the $r$ and dhod genes are transcribed abundantly (dhod from a special male-limited transcriptional start) during spermatocyte development in Drosophila. However, the proteins are not translated from mRNA until several days later, during spermatid differentiation, and thus DHODH and CAD are present in mature Drosophila spermatozoa. In contrast, the $r-l$ gene is transcribed for a much shorter period, only during gonial cell divisions, and the UMPS protein is not detected in spermatids or spermatozoa. Thus, only a truncated pathway for UMP synthesis is found in Drosophila sperm cells.

$\mathrm{DHODH}$ protein has been detected in the mitochondria of ejaculated mature bull and human spermatozoa (Dietz et al., 2000) using immunocytochemistry, immunoblot 


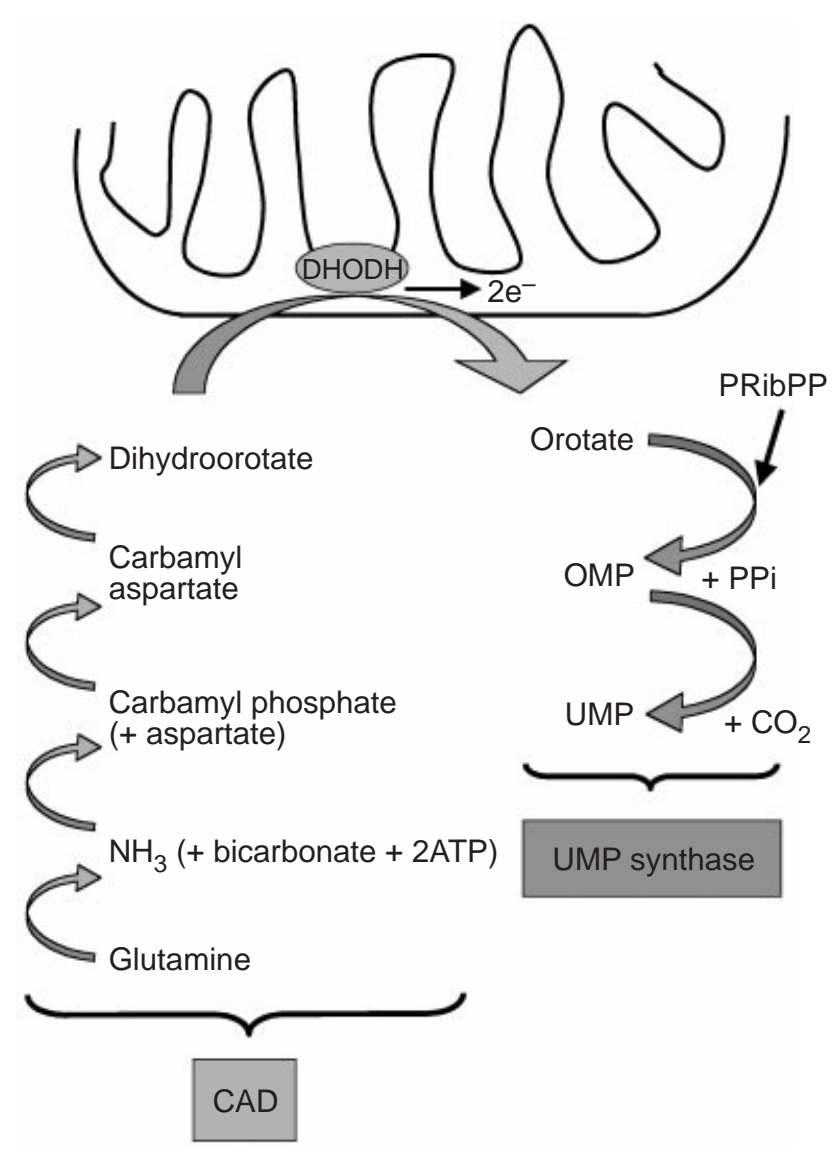

Fig. 1. The de novo biosynthetic pathway for the pyrimidine nucleotide uridine monophosphate (UMP) in mammals. Most of the biosynthetic pathway is catalysed in the cytoplasm and is linked to the respiratory chain through the fourth enzyme, ubiquinone-dependent dihydroorotate dehydrogenase (DHODH) in the inner mitochondrial membrane. The multi-enzyme polypeptide glutamine-dependent carbamyl phosphate synthetase, aspartate transcarbamylase and dihydroorotase (CAD) contains the enzyme activities for reactions 1-3. Reaction 1 includes the donation of ammonia from the obligate substrate glutamine (step 1a) and the synthesis of carbamyl phosphate using two molecules of ATP (step 1b). The bifunctional polypeptide UMP synthase contains the enzyme activities for steps 5 and 6: orotate phosphoribosyltransferase and orotidine $5^{\prime}$ monophosphate decarboxylase. PRibPP: 5-phosphoribosyl 1-pyrophosphate.

analysis of extracted proteins and specific enzyme activity, and by detecting the activity of the enzyme in spermatozoa in the seminiferous tubules (Löffler et al., 1996). The finding that $\mathrm{DHODH}$ is located in the mitochondrial inner membrane in fibroblasts (Chen and Jones, 1976; Rawls et al., 2000) led us to compare UMP synthesis with the urea cycle, in which channelling between the enzymes in the cytoplasm and mitochondria has already been demonstrated (Cheung et al., 1989; Watford, 1991) (Fig. 1). Because CAD and UMPS are obtained in the cytosolic fraction when prepared from cell extracts, they would be expected to cluster on the outer surface of mitochondria rather than attach to or become integrated in the membrane, because neither protein has a mitochondrial targeting sequence (Suttle et al., 1988; Guy and Evans, 1994) as has been shown for DHODH (Rawls et al., 2000). ATP is required for the biosynthesis of carbamyl phosphate and for the synthesis of 5-phosphoribosyl 1-pyrophosphate (PRibPP) for step 5, and would be conveniently provided from the mitochondrion. The mitochondrion may also be a source of bicarbonate ion for the synthesis of carbamyl phosphate. If CAD and UMPS molecules are found near the mitochondrion, small metabolites can be dedicated (channelled) to use in the biosynthetic pathway without leaching out into solution.

If CAD were present near the mitochondria of spermatozoa, it would provide dihydroorotate as a substrate for $\mathrm{DHODH}$ to convert to orotate, also generating electrons that can be transferred via ubiquinone to the respiratory electron transfer chain. Porter et al. (1995) suggested that these electrons might have a downstream redox effect that is important in the motility of spermatozoa. Dietz et al. (2000) proposed that the production of orotate might play a role in the maturation of spermatozoa, in sustaining morphology or in modulating motility, whereas the electrons may repay some of the energy cost for biosynthesis. The presence of UMPS in spermatozoa would complete the biosynthetic pathway and allow the further use of orotate for synthesis of UMP; however, as there is no DNA or RNA synthesis in mature spermatozoa, there is no apparent role for newly synthesized nucleotides.

In this study, immunoblot analysis and immunocytochemistry were used to determine whether mammalian spermatozoa contain both CAD and UMPS. Mammalian fibroblasts, in which enzymes for all six steps are present, were used to confirm methods of detection.

\section{Materials and Methods}

\section{Antibody production}

Antibodies were generated against synthetic peptides corresponding to the two sites in the multi-enzyme polypeptide CAD that are known to be phosphorylated by protein kinase A. Peptides S1 and S2 correspond to the sequences of phosphorylation sites 1 and 2, respectively (Carrey and Hardie, 1988). These peptides, each of 16-18 amino acids, were synthesized by Bristol Peptides (G. Bloomberg, Department of Biochemistry, School of Medical Sciences, University of Bristol, Bristol) and inoculated into sheep (Fig. 2). The antibodies were separated by affinity chromatography on columns to which each peptide had been bound separately (Harlow and Lane, 1988). The sera and antibody preparations are referred to as 'anti-S1' and 'anti-S2'.

A similar procedure was adopted using peptides corresponding to sequences in the other cytoplasmic enzyme activities of pyrimidine biosynthesis. A sequence from the aspartate transcarbamylase (ATCase) domain in CAD was 


$\begin{array}{lll}\text { Name } & \text { Sequence } & \text { Identity of epitope } \\ \text { S1 } & \text { RGAGGRRLSSFVTKGYR } & \text { CAD residues 1398-1414 (PKA site 1) } \\ \text { S2 } & \text { HLPPRIHRASDPGLPAEE } & \text { CAD residues 1850-1867 (PKA site 2) } \\ \text { SIE } & \text { SIEEALPDTDVLYMTR } & \text { CAD residues 2130-2145 (ATCase domain) } \\ \text { LRG } & \text { LRGIVSRPRLLSQVAD } & \text { UMPS residues 40-55 (OPRTase domain) } \\ \text { EYN } & \text { EYNSPQEVIGKRGSDI } & \text { UMPS residues 431-446 (OMP decarboxylase domain) }\end{array}$

Fig. 2. Sequences of synthetic peptides used as immunogens. Synthetic polypeptides corresponding to portions of glutamine-dependent carbamyl phosphate synthetase, aspartate transcarbamylase and dihydroorotase (CAD) or uridine monophosphate synthase (UMPS) were inoculated into sheep (S1 and S2) or rabbits (SIE, LRG and EYN) and the resulting antibodies were affinity-purified against the same peptides. ATCase: aspartate transcarbamylase; OMP: orotidine 5' monophosphate; OPRTase: orotate phosphoribosyltransferase; PKA: protein kinase A.

chosen because the same region in the homologous catalytic subunit of the E. coli ATCase is known to be accessible to solvent (Scully and Evans, 1991). Two sections of 16 residues, one from each of the enzyme activities in UMPS, were chosen from the published sequence (Suttle et al., 1988) to include charged and polar residues that are more likely to occur on the surface of the molecule. These peptides were inoculated in pairs into three rabbits, giving the opportunity of two antibody preparations for each peptide, after separation on affinity columns as described above.

The anti-DHODH antibody was the affinity-purified antibody raised in rabbits against recombinant human $\mathrm{DHODH}$ described by Dietz et al. (2000). Another anti-UMPS serum was provided by T. Traut (University of North Carolina, Chapel Hill) (Han et al., 1995).

\section{Cells (growth of cell lines and collection of spermatozoa)}

The hamster fibroblast cell lines were grown in Dulbecco's modified Eagle's medium with $10 \%$ fetal calf serum using standard methods. The over-producing cell line was originally derived by selection against the transitionstate analogue phosphonacetyl L-aspartate (Kempe et al., 1976) and has been re-selected against the analogue to eliminate cells that do not over-produce the CAD protein. The 'parental' cell line, baby hamster kidney (BHK)-21 clone 3, was obtained from the European Collection of Animal Cell Cultures (CAMR, Salisbury).

Semen was collected from bulls and rams by artificial vagina from Al (artificial insemination) animals held at the Genus Breeding Centre (bulls) and the Royal Veterinary College (rams). Boar semen was collected by the gloved hand method from Al boars at the Gene Transfer Centre (South) of PIC (UK). Ram semen was diluted into RPMI1640 medium for biochemical investigation or into PBS for preparation of smears on microscope slides. Bull and boar semen were each diluted into commercial transport diluent for transfer to the Royal Veterinary College at dilutions of about 20-40 $\times 10^{6}$ spermatozoa $\mathrm{ml}^{-1}$. The ejaculates of these stud animals are of high density, and have high sperm viability and little contamination by other cells; therefore, the swim-up procedure was unnecessary to select a highly motile sperm population.

Human semen was collected from healthy volunteers and spermatozoa were purified using the swim-up procedure as described by Dietz et al. (2000).

\section{Immunocytochemistry}

Hamster fibroblasts were grown on sterile multi-chamber slides (Sterilin) to allow parallel treatment of cells in the fixing and staining processes. The cells were fixed on the surface of the chambers with $0.5 \%(\mathrm{v} / \mathrm{v})$ glutaraldehyde in $200 \mathrm{mmol}$ piperazine- $\mathrm{N}, \mathrm{N}^{\prime}$-bis(2-ethanesulphonic acid) (PIPES) buffer $\mathrm{l}^{-1}, \mathrm{pH} 7.2$, for $30 \mathrm{~min}$ at room temperature, washed with distilled water and then air-dried. For fluorescent immunocytochemistry, the cells were permeabilized with $1 \%(\mathrm{v} / \mathrm{v})$ Triton-X100 in PBS $\left(0.1\right.$ mol phosphate $\mathrm{I}^{-1}$,

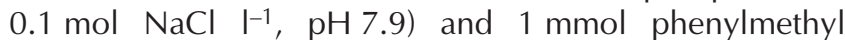
sulphonyl fluoride (PMSF) $\mathrm{I}^{-1}$ for $5 \mathrm{~min}$. Non-specific binding sites were blocked with $2 \%(\mathrm{w} / \mathrm{v}) \mathrm{BSA}$ in PBS, before each chamber of the slides was flooded with the relevant primary antibody diluted with PBS. The cells were exposed to the primary antibody for $1 \mathrm{~h}$ at room temperature and subsequently the secondary antibody (linked to the fluorophores tetramethylrhodamine isothiocyanate (TRITC) or fluorescein isothiocyanate (FITC); anti-rabbit or anti-sheep; from DAKO, Ely) for $1 \mathrm{~h}$ in the dark. Between each stage, the slides were washed thoroughly with PBS, and the dividing walls between the chambers were removed before the final step of the process. The mounting agent and coverslide were placed in position just before the slides were viewed on the Zeiss LSM 510 confocal microscope with a Zeiss Fluar $\times 40 / 1.3$ oil Ph3 objective, using excitation wavelengths of $488 \mathrm{~nm}$ (argon laser) for FITC-stained slides and $543 \mathrm{~nm}$ (helium-neon laser) for TRITC-stained slides.

Spermatozoa to be used for confocal fluorescent microscopy were washed in PBS and $1 \mathrm{mmol} \mathrm{PMSF} \mathrm{I-1}^{-1}$, and diluted to a final concentration of $2-5 \times 10^{7}$ cells $\mathrm{ml}^{-1}$. Samples of $100 \mu \mathrm{l}$ were then smeared on to glass microscope slides and air-dried. Permeabilization, blocking and antibody binding were carried out as described above, except that after permeabilization, the cells were fixed by 
(a)

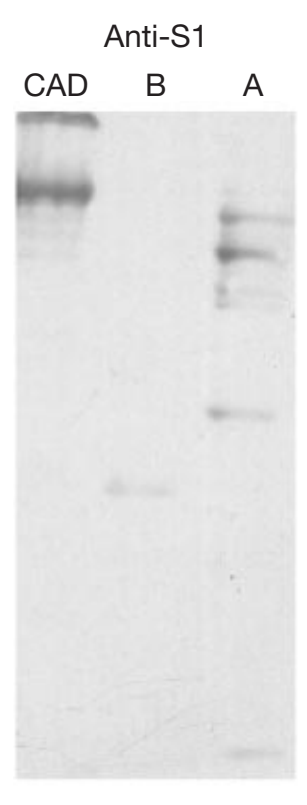

(b)

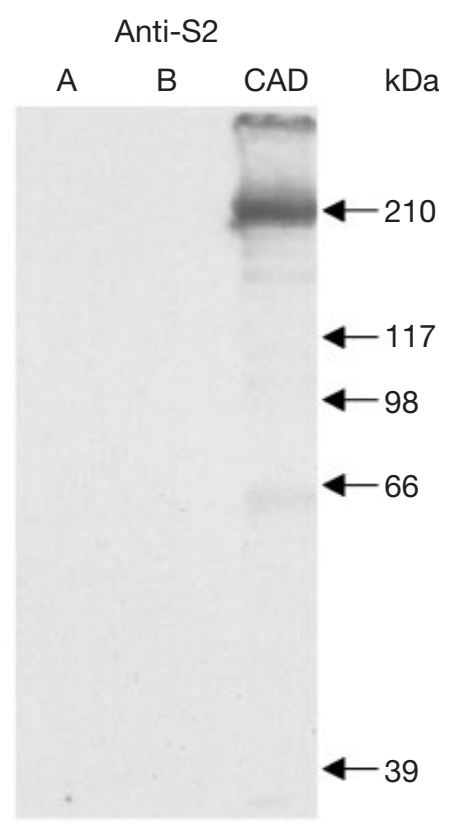

rab Anti-S1

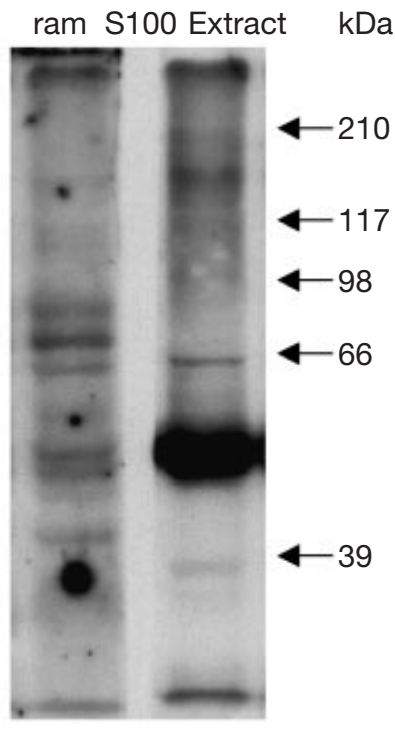

Fig. 3. Reaction of glutamine-dependent carbamyl phosphate synthetase, aspartate transcarbamylase and dihydroorotase (CAD) with the affinity-purified sheep antibodies. Sera raised in sheep by inoculation with synthetic peptides (S1 and S2) were used in immunoblotting experiments at a dilution of 1:5000. (a) The reaction of protein bands separated after limited digestion of CAD by trypsin. Digestion proceeded for $45 \mathrm{~min}$ at $37^{\circ} \mathrm{C}$ with trypsin: CAD ratios of $1: 1000$ (A) and 1:100 (B). Anti-S1 antibody reacts with the carbamoyl phosphate synthetase core protein of $150 \mathrm{kDa}$ and 'nicked CAD' of $190 \mathrm{kDa}$; anti-S2 antibody reacts only with intact CAD of $240 \mathrm{kDa}$, which runs close to the myosin standard. (b) The bands from a soluble extract (S100) of ram spermatozoa. Antisera were a rabbit anti-CAD serum, developed for electrochemiluminescence with anti-rabbit IgG; and anti-S1, developed with anti-sheep IgG. The prominent band at $53 \mathrm{kDa}$ is seen in the control lanes (no first antibody or pre-immune sheep antibody: not shown) and appears to be specific to extracts from ram spermatozoa developed with anti-sheep $\lg \mathrm{G}$.

immersion for 5 min in buffered formal saline and washed with distilled water before proceeding with the blocking steps.

For electron microscopy, both sperm cells and fibroblasts were fixed at an ambient temperature for $30 \mathrm{~min}$ in $0.5 \%$ $(\mathrm{v} / \mathrm{v})$ glutaraldehyde in 200 mmol PIPES buffer $\mathrm{I}^{-1}, \mathrm{pH}$ 7.2. Spermatozoa were centrifuged during fixation at approximately $15800 \mathrm{~g}$ in a microcentrifuge, and the solid pellets were then washed in PBS and stored at $4^{\circ} \mathrm{C}$. Cultured cells were washed in PBS, scraped from the flask and then pelleted at $15800 \mathrm{~g}$. Pellets were cryoprotected in $2.1 \mathrm{~mol}$ sucrose $\mathrm{I}^{-1}$ in PBS for at least 30 min before being frozen in liquid nitrogen and cut into sections on a Leica ultracryomicrotome. Ultrathin (unstained) cryosections were cut at a nominal 50-100 nm and labelled with primary sheep antibodies detected using rabbit anti-sheep antibodies followed by protein A gold (Lucocq, 1992). The density of gold labelling was estimated using stereological techniques as described previously (Lucocq, 1994; Deak et al., 1998).

\section{Preparation of cell extracts for electrophoresis}

CAD is prepared routinely from the post-mitochondrial supernatant of an extract of the over-producing cell line (Coleman et al., 1977); thus, a sample of this supernatant from both the over-producing and 'parental' BHK-21 cells (clone 3) was used in SDS-PAGE. Subsequent immunoblotting, in which the proteins on the surface of the membrane are regarded as having regained the native conformation, was used to screen for appropriate antibodies with a positive band at the expected molecular mass for CAD (> $220 \mathrm{kDa}$ ) or UMPS (50 kDa). The antibodies used in the present study identified both proteins in blots from the post-mitochondrial supernatant from fibroblast extracts, and samples of these extracts were used as controls with the extracts from spermatozoa.

Because CAD is vulnerable to attack by proteases, yielding a range of smaller fragments that will crossreact in the immunoblotting process, the extraction methods used in the present study for spermatozoa included high concen- 
trations of protease inhibitors (ten times higher than usual). Boar or ram spermatozoa were washed, homogenized in hypotonic buffer in the presence of protease inhibitors and boiled for 2 min in electrophoresis buffer (Lämmli, 1970). The boiled extract was centrifuged at $15800 \mathrm{~g}$ for $2 \mathrm{~min}$ and the supernatant was used on the gel. This extract was the total extract of the cells. A further sample of spermatozoa was homogenized as above and then separated by centrifugation at $10000 \mathrm{~g}$ for $10 \mathrm{~min}$ at $4^{\circ} \mathrm{C}$ : the pellet was P10 and the supernatant was separated by centrifugation at $100000 \mathrm{~g}$ for $1 \mathrm{~h}$ at $4^{\circ} \mathrm{C}$ into pellet (P100) and supernatant (S100). Each sample was resuspended in electrophoresis buffer so that similar volumes were equivalent to the same number of spermatozoa used in the extraction. After boiling, only P10 formed a precipitate when centrifuged at $15800 \mathrm{~g}$ (the supernatant was applied to the gel), confirming that this sample contained the sperm nuclei (Travis et al., 1998). The P100 and S100 extracts corresponded to membrane proteins and soluble proteins, respectively. Samples were run in 6.5 or $7.5 \%(\mathrm{w} / \mathrm{v})$ acrylamide mini-gels in SDS-PAGE (Lämmli, 1970).

Extracts of human spermatozoa were obtained and processed as described by Dietz et al. (2000).

\section{Immunolabelling and electrochemiluminescence of blots}

After electrophoresis, the proteins were transferred to a membrane (Immobilon P, Millipore) by semi-dry blotting for $90 \mathrm{~min}$ at a fixed voltage that delivers a current of $0.8 \mathrm{~mA}$ per $\mathrm{cm}^{2}$ using the Pegasus blotter (PHASE, Lübeck). Lanes were identified by temporary stain with $0.1 \%(\mathrm{w} / \mathrm{v})$ brilliant blue $\mathrm{R}$ (Serva) in $50 \%$ (v/v) methanol or by Ponceau red stain, followed by immunostaining and electrochemiluminescent (ECL) development using the reagents and instructions from Amersham Pharmacia Biotech. Lanes containing molecular mass markers were cut from the membrane and then stained permanently with $0.1 \%(\mathrm{w} / \mathrm{v})$ brilliant blue $\mathrm{R}$ in $40 \%(\mathrm{v} / \mathrm{v})$ methanol and $1 \%(\mathrm{v} / \mathrm{v})$ acetic acid, followed by destaining in 50\% (v/v) methanol.

\section{Results}

\section{Specificity of antibodies}

Antibodies raised against synthetic peptides from the CAD sequence are potentially very specific as the immunogenic epitope corresponds to such a small part of the large protein molecule, and as they were purified by affinity chromatography using peptides similar to the immunogens. The specificity of these antibodies (from both sheep and rabbits) was confirmed by immunoblotting against intact CAD and against fragments of CAD generated by limited digestion with trypsin (Carrey and Hardie, 1988). For example, the anti-S1 antibody reacted with intact CAD and with the fragments known to contain the C-terminal domains of carbamoyl phosphate synthetase (CPS) II (including 'nicked $\mathrm{CAD}^{\prime}$ at $190 \mathrm{kDa}$ ), and the anti-ATCase antibody reacted with CAD and with the appropriate fragment of approxi-
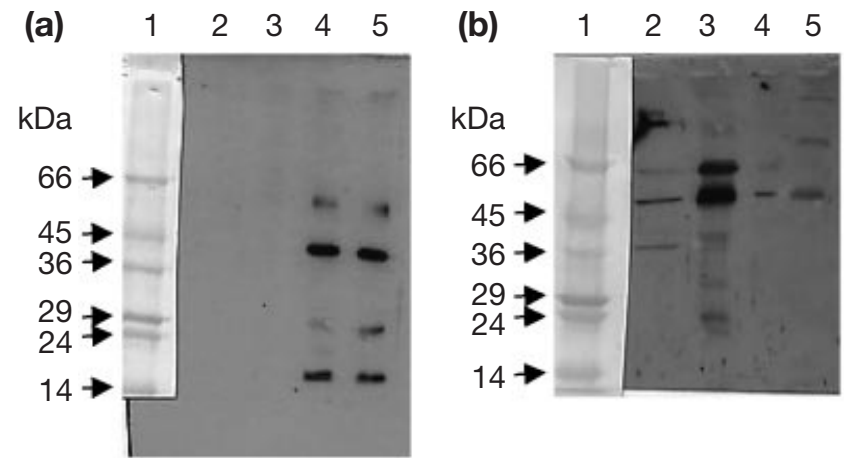

Fig. 4. Reaction of antibodies with dihydroorotate dehydrogenase $(\mathrm{DHODH})$ and uridine monophosphate synthase (UMPS) proteins in cell extracts. (a) Preparations from boar spermatozoa in immunoblotting experiments (same conditions as described by Dietz et al., 2000) with the affinity-purified antibody raised against $\mathrm{DHODH}$. Lane 1, molecular mass standards (stained blot); lanes 2-5, electrochemiluminescence of extracts as follows: lane 2, S100; lane 3, P100; lane 4, P10; lane 5, total extract. (b) The reaction of the Traut/Jones anti-UMPS antibody against cell preparations as follows: lane 2, rat pancreatic cytosol; lane 3, human spermatozoa S100; lane 4, cytosol of over-producing hamster cells; lane 5, ram spermatozoa S100.

mately $40 \mathrm{kDa}$. In contrast, the anti-S2 antibody reacted only with intact CAD (Fig. 3a), as the region of CAD that contains the epitope is lost early in the limited digestion of CAD by trypsin (Carrey and Hardie, 1988). Attempts were made to confirm the specificity by adding the relevant peptide $(\mathrm{S} 1, \mathrm{~S} 2)$ to the immunoblot interaction, to prevent the binding of the sheep antibodies. The peptides were not able to displace the antibodies from the blotted protein, indicating that the antibodies had a very high affinity for the relevant epitopes of CAD. Thus, although the affinitypurified antibodies may still contain several populations with different crossreactivities, the specificity for the relevant region of the target protein appears to be absolute.

Rabbit antiserum 40, which had been raised against peptides from each domain of UMPS, reacted with a protein of approximately $50 \mathrm{kDa}$, as expected for UMPS, in the soluble fraction of an extract prepared from the BHK-21 clone 3 cells (not shown).

When immunoblots were incubated for long periods or without sufficient blocking reagent, it was noted that some molecular mass standards were recognized strongly by antirabbit secondary antibody. Similarly, anti-sheep antibody (with no primary antibody incubation or with pre-immune serum) recognized a 47-53 kDa band in ram sperm extract, as shown in the experimental lane (Fig. 3b) and the control lanes (not shown).

\section{Identification of proteins in cell extracts by immunoblot analysis}

The affinity-purified anti-DHODH antibody detected $\mathrm{DHODH}$ in the total extract of boar spermatozoa and also in the P10 extract, corresponding to the fraction containing nuclei and mitochondria (Fig. 4a). No DHODH was 

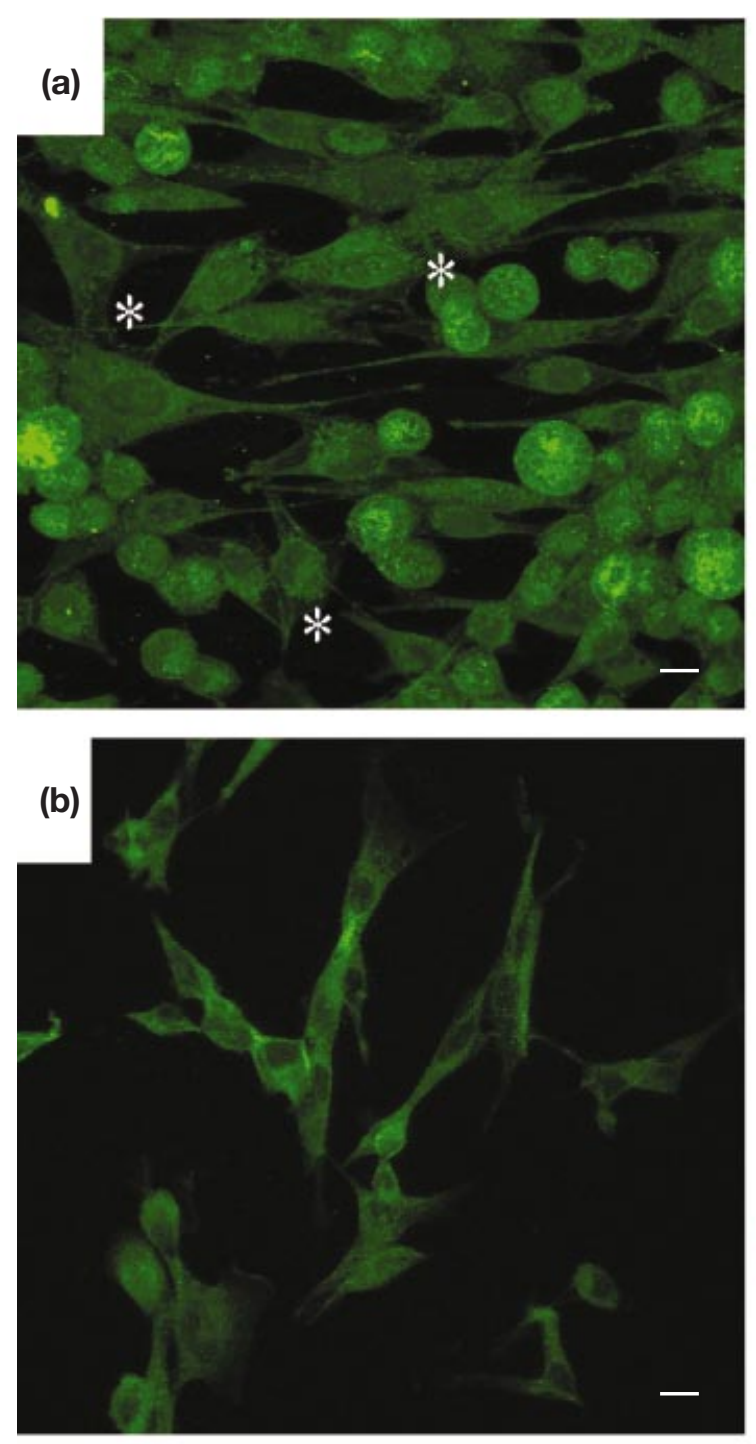

(c)

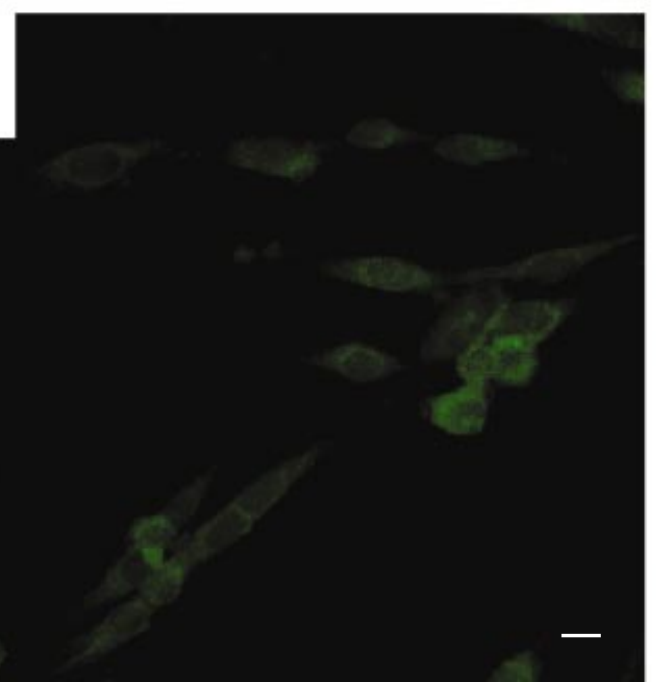

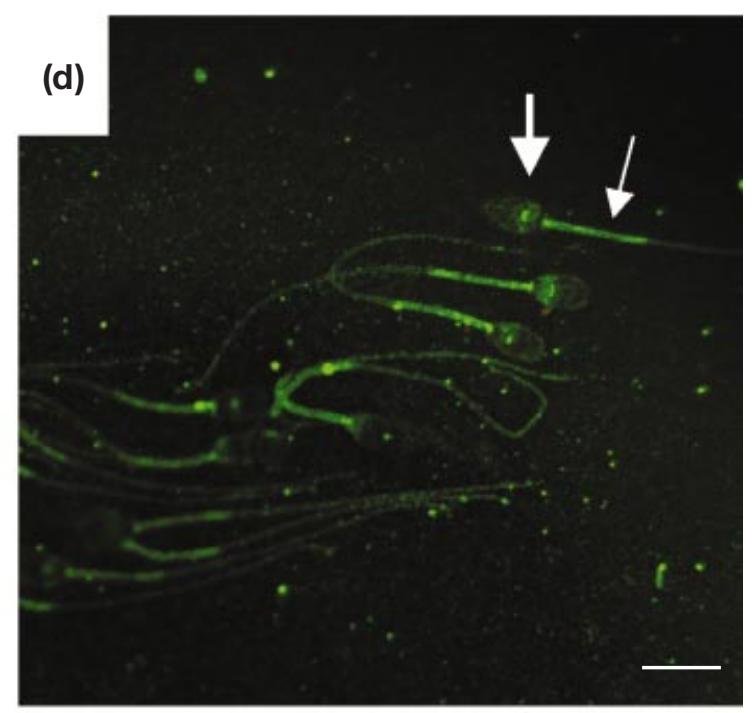

(e)

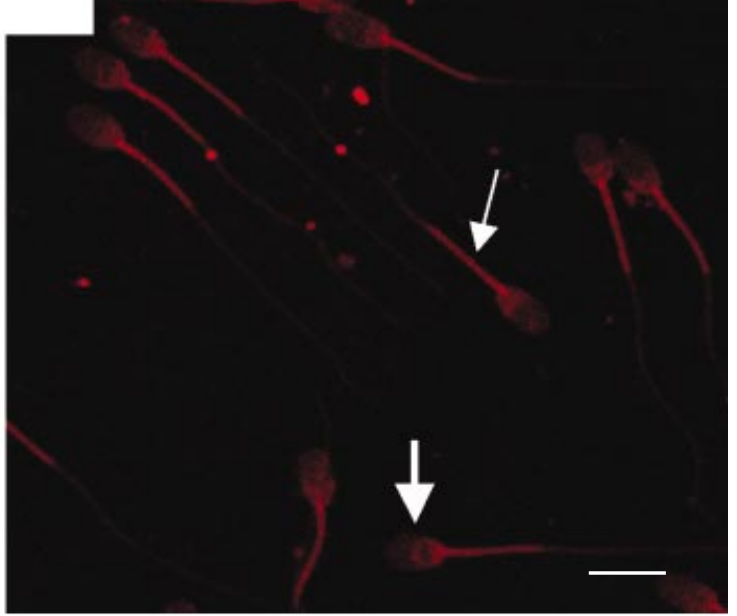

(f)

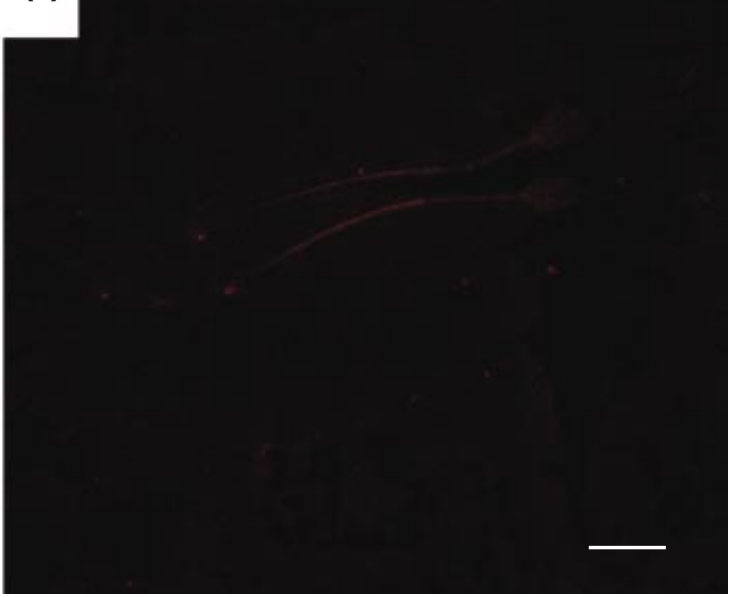

Fig. 5. Immunofluorescent labelling of glutamine-dependent carbamyl phosphate synthetase, aspartate transcarbamylase and dihydroorotase (CAD) and uridine monophosphate synthase (UMPS) protein in baby hamster kidney (BHK) fibroblasts and in ram spermatozoa. Cells were labelled with specific antibody or with rabbit pre-immune serum, 

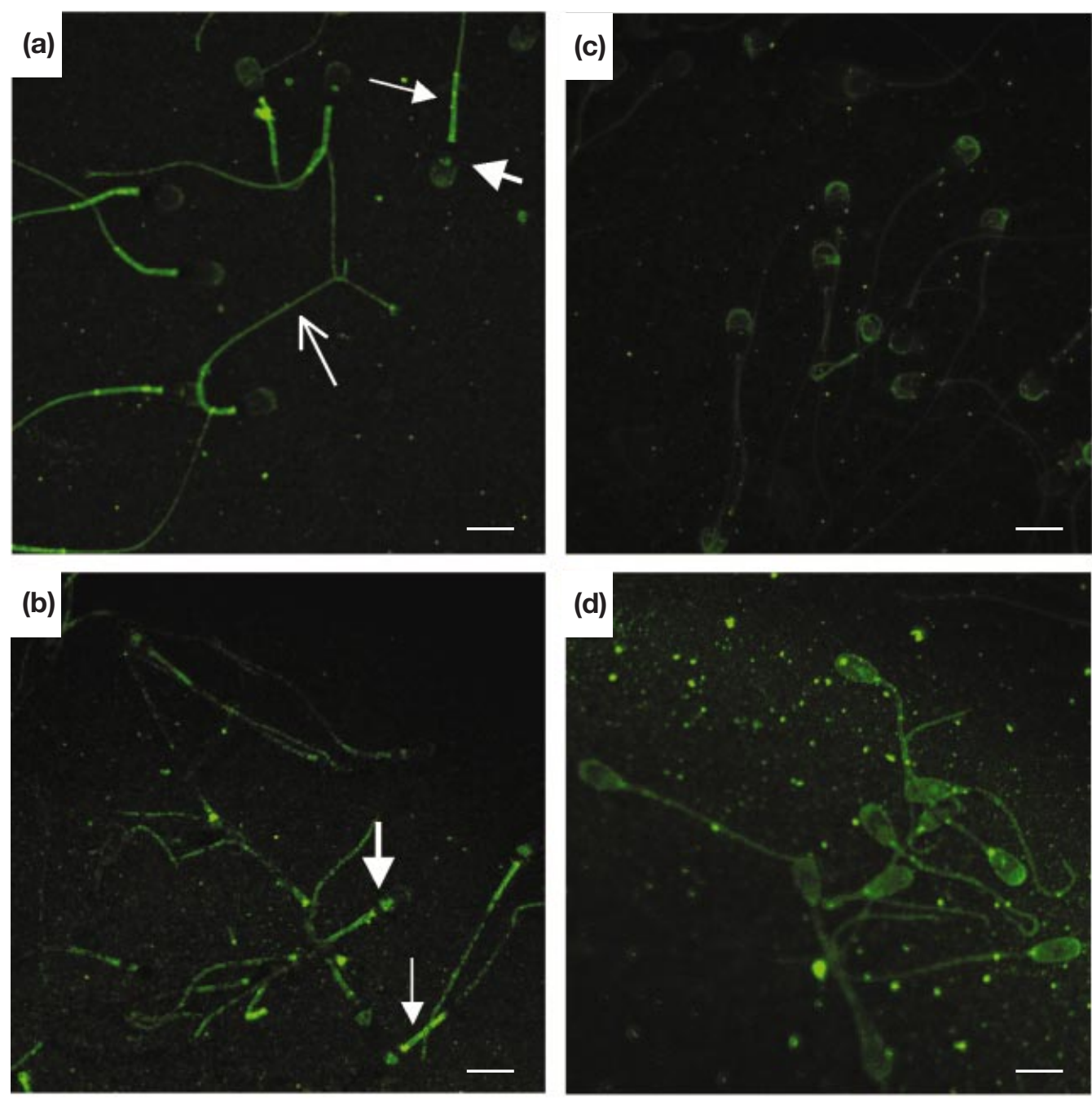

Fig. 6. Distribution of glutamine-dependent carbamyl phosphate synthetase, aspartate transcarbamylase and dihydroorotase (CAD) protein in bull and boar spermatozoa shown by immunofluorescent labelling. Samples were fixed, permeabilized and reacted with specific antiserum and then exposed to fluorescein isothiocyanate (FITC)-labelled anti-sheep antibody. (a,c) Bull spermatozoa and (b,d) boar spermatozoa. Antibodies were: $(a, b)$ anti-S2 and (c,d) pre-immune serum. Thick arrows indicate fluorescence in the equatorial segment of the sperm head; thin arrows, in the mid-piece; and the open arrow, in the tail of bull spermatozoa. Scale bars represent $10 \mu \mathrm{m}$.

detected in the P100 or S100 fractions, confirming the expected distribution (Dietz et al., 2000).

When authentic UMPS was used as the immunogen (Han et al., 1995), the resulting antiserum reacted with bands at 66 and $50 \mathrm{kDa}$ in a soluble extract from fibroblasts and in the S100 extract from ram and human spermatozoa (Fig. 4b). This finding confirms that UMPS is present in the soluble portion of the cells. The band at $28-29 \mathrm{kDa}$ is thought to correspond to the orotidine decarboxylase domain resulting from partial digestion of the UMPS molecule (Floyd and Jones, 1982; Han et al., 1995).

Attempts at detecting CAD in soluble extracts from spermatozoa were much less successful. The bands from a soluble extract (S100) of ram spermatozoa is shown (Fig. 3b). A rabbit serum, raised against purified CAD, reacted with a series of bands representing impurities seen in all extracts and by the anti-rabbit antiserum alone. The lane developed with anti-S1 immunoglobulin had a prominent

and then with fluorescein isothiocyanate (FITC)-labelled or tetramethylrhodamine isothiocyanate (TRITC)-labelled secondary antibody. $(\mathrm{a}-\mathrm{c})$ BHK-21 clone 3 cells; (d-f) ram spermatozoa. Antibodies were: (a,d) anti-S2; (b) anti-UMPS [serum 40]; (e) anti-EYN; (c,f) pre-immune serum. Thick arrows indicate fluorescence in the equatorial segment of the sperm head; thin arrows indicate fluorescence in the mid-piece. Asterisks indicate cells in which labelling appears to follow the cytoskeletal network. Scale bars represent $10 \mu \mathrm{m}$. 

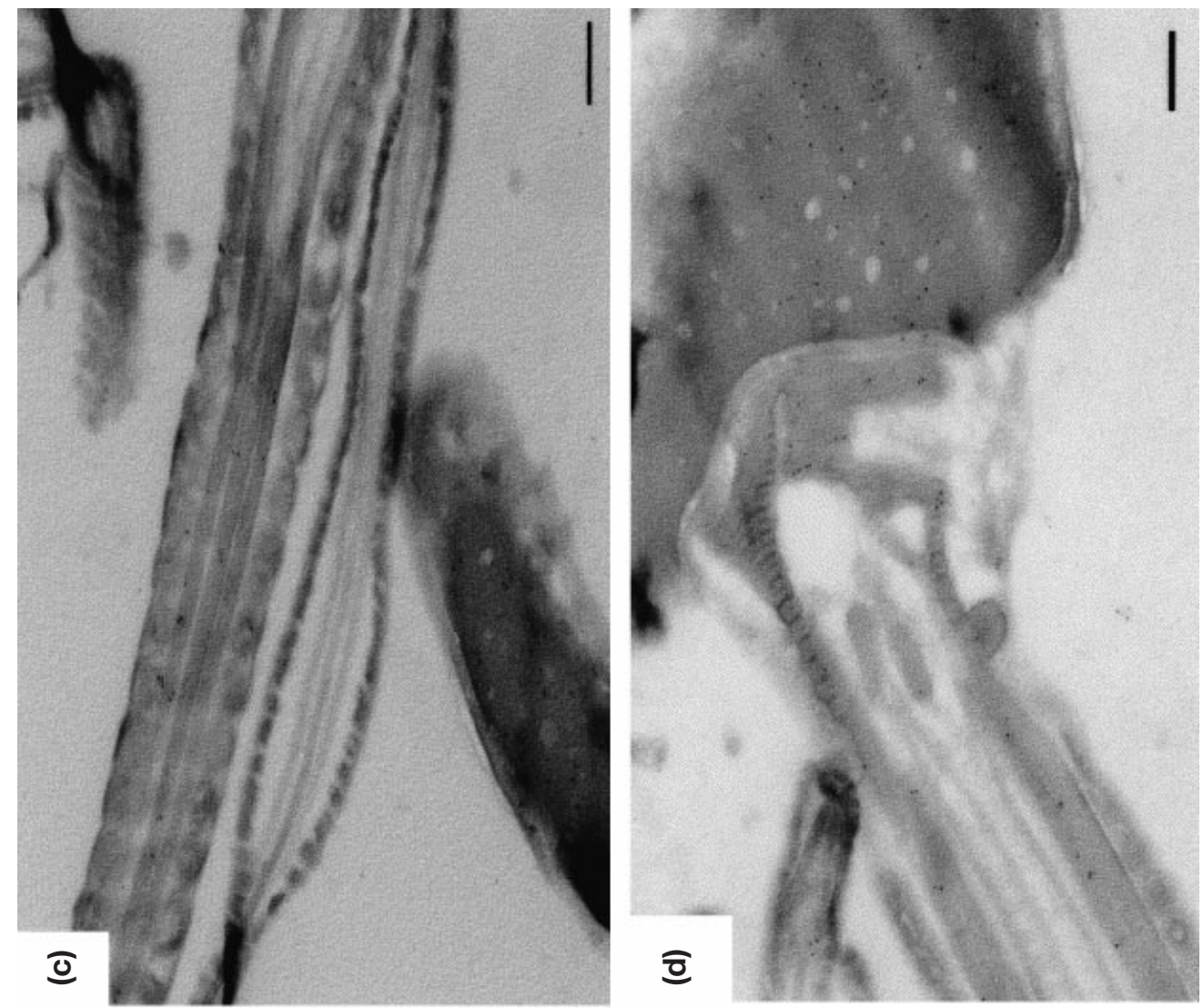

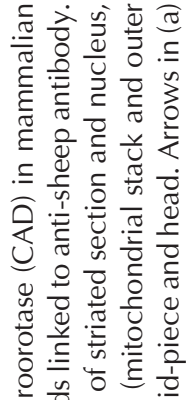

은 先

产这

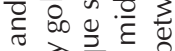

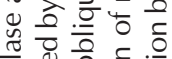

है 을

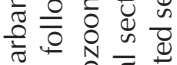

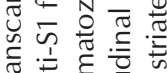

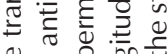

혼

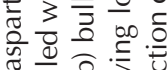

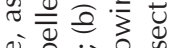

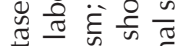

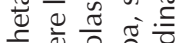

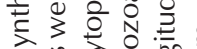

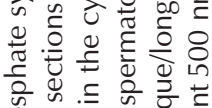
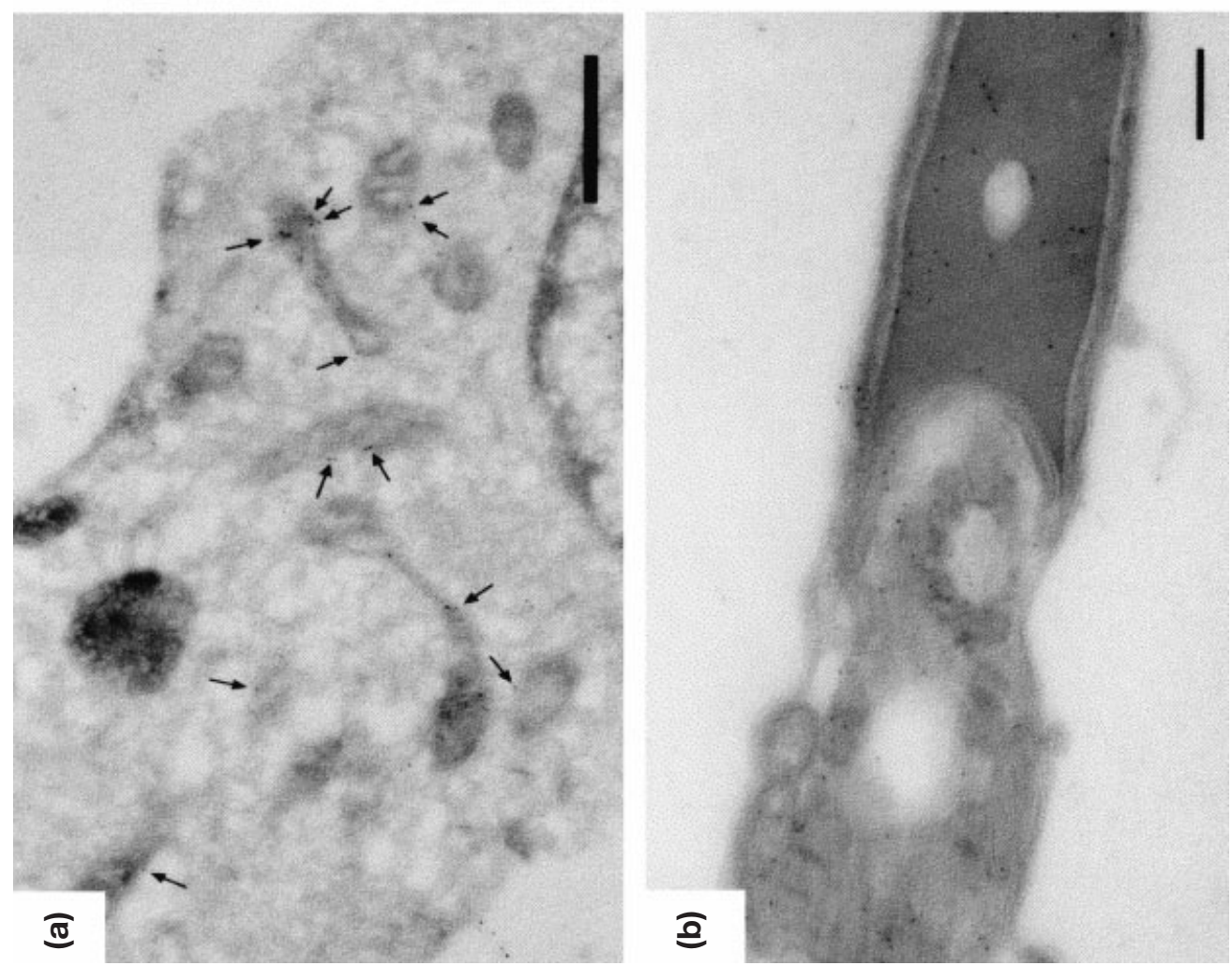

क

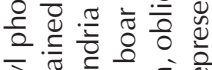

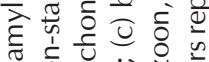

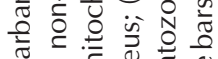

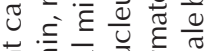

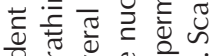

这步

눙

d

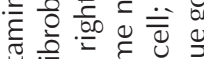

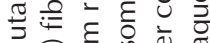

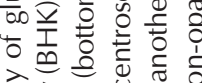

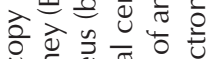

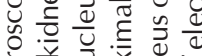

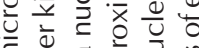

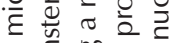

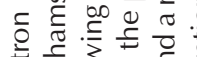

屯 उั

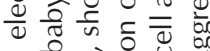

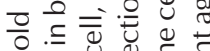

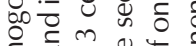

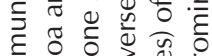

हो

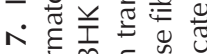

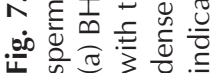


band at $53 \mathrm{kDa}$, which was also seen in lanes developed with preimmune serum or no first antibody. Bands corresponding to CAD and 'nicked CAD' were recognized by anti-S1 in this preparation of ram spermatozoa. Not only may CAD be sparse in spermatozoa but also the protein may be poorly transferred into the blotting membrane, as myosin standard was also transferred to Immobilon P less efficiently than the lower molecular mass proteins.

\section{Identification and location of proteins in intact cells}

Fluorescent immunolabelling of BHK cells. Fluorescent immunolabelling and confocal microscopy confirm that the antibodies used in the present study can detect all the enzymes for UMP synthesis in cells from the BHK-21 clone 3.

The location of CAD, in cells fixed in situ, was probed with sheep antisera raised against peptides S1 and S2. Immunofluorescence located the epitope corresponding to $\mathrm{S} 2$ in the cytoplasm with a net-like distribution similar to a cytoskeletal element, and in some very bright spots over the nucleus (Fig. 5a) with very intense immunofluorescence in rounded and dividing cells. The distribution of the S1 epitope (not shown) was similar.

The presence of DHODH and UMPS in fibroblasts was probed either with the affinity-purified rabbit antibody (anti$\mathrm{DHODH})$ or with an unfractionated serum raised against peptides from UMPS (rabbit serum 40, containing both anti-EYN and anti-LRG). The immunofluorescence (Fig. 5b shows UMPS detected by serum 40) confirmed that both proteins were located in the cytoplasm, and that neither was found in the nucleus. The fluorescence shown by anti$\mathrm{DHODH}$ was not high enough to distinguish a punctate distribution equivalent to that in the mitochondria, as expected from previous studies (Dietz et al., 2000; Rawls et al., 2000).

Fluorescent immunolabelling of spermatozoa. The distribution of CAD protein as shown by immunofluorescence was similar in spermatozoa from rams, bulls and boars (Figs 5d, 6a,b). In spermatozoa, the mitochondria are packed in a regular array in the mid-piece, between the head and the flexible flagellum, all surrounded by a thin coat of cytoplasm (Curry and Watson, 1995); thus, they can be readily distinguished from other organelles. In these three species, sheep anti-S1 (not shown) and anti-S2 stained the mid-piece intensely, and in many cells bright fluorescence was also observed in the centriole region near to the head. Staining in the bull spermatozoa extended along the entire length of the tail (Fig. 6a,c). Anti-S2 was also seen in a 'cone' of bright fluorescence in the head of spermatozoa from all three species. The location and shape of the fluorescent signal corresponds to the equatorial segment of the acrosome, a thin area of cytoplasm that usually remains attached to the head after the acrosome reaction (Watson, 1975).

The antibody raised against $\mathrm{DHODH}$ gave a weaker fluorescent signal in the mid-piece (not shown). Permeabilization of the plasma membrane with Triton-X100 provided an optimal system for the detection of CAD, but the process differed from the method used by Dietz et al. (2000) to detect $\mathrm{DHODH}$ and it may have been less efficient in permeabilizing the mitochondria. The fluorescent signal attached to anti-DHODH antibody was never observed in the head region of spermatozoa.

Affinity-purified antibodies raised against the OMP decarboxylase domain of UMPS were observed in ram spermatozoa staining the mid-piece strongly, and in the back part of the head (Fig. 5e) in some cells. The latter distribution may correspond to the thin coat of cytoplasm found in the postacrosomal region and the equatorial region, although it is not as distinct as the staining with anti-S2.

\section{Immunogold electron microscopy}

The distribution of the enzymes was also investigated using immunogold electron microscopy. Labelling for CAD in BHK-21 clone 3 cells (Fig. 7a) was found around the mitochondria closely associated with the outer membrane. The density of labelling was 5.2-fold higher in the cytoplasm compared with the nucleus, indicating that the majority of CAD molecules were present in the cytoplasm of these cells, where the cytoplasm is a larger compartment than the nucleus.

In fixed spermatozoa, labelling was concentrated in the mid-piece among the outer dense fibres and around the outside of the mitochondria (Figs 7c, 8b). In other sections, labelling was concentrated in the segmented section of the mid-piece between the mitochondrial stack and the centriole at the head end of the mid-piece (Fig. 7b,d), corresponding to the highly fluorescent area seen using confocal microscopy. A significant amount of gold labelling was also detected in the nucleus of spermatozoa from boars, bulls (Fig. 7b,c,d) and rams (Fig. 8).

\section{Discussion}

The multi-enzyme proteins CAD and UMPS can be purified separately from the soluble fraction of cells or tissues, and their enzyme activities have been studied extensively (Shaw and Carrey, 1992; Irvine et al, 1997). An immunocytochemical study of the location of CAD in BHK fibroblasts, using polyclonal antisera (Chaparian and Evans, 1988), showed a 'punctate distribution' of the protein throughout the cytoplasm that the authors nevertheless did not identify as mitochondria. In subcellular fractions, they found only $2 \%$ of the ATCase activity of CAD with the mitochondrial fractions, whereas $30 \%$ of the activity was associated with the nuclear fraction, a higher amount than that indicated by the intensity of staining in the nucleus. However, Chaparian and Evans (1988) also noted that a soluble extract from 'purified' nuclei contained about $4 \%$ of the ATCase activity, an amount that could arise from contamination and, therefore, these authors concluded only that the CAD mole- 

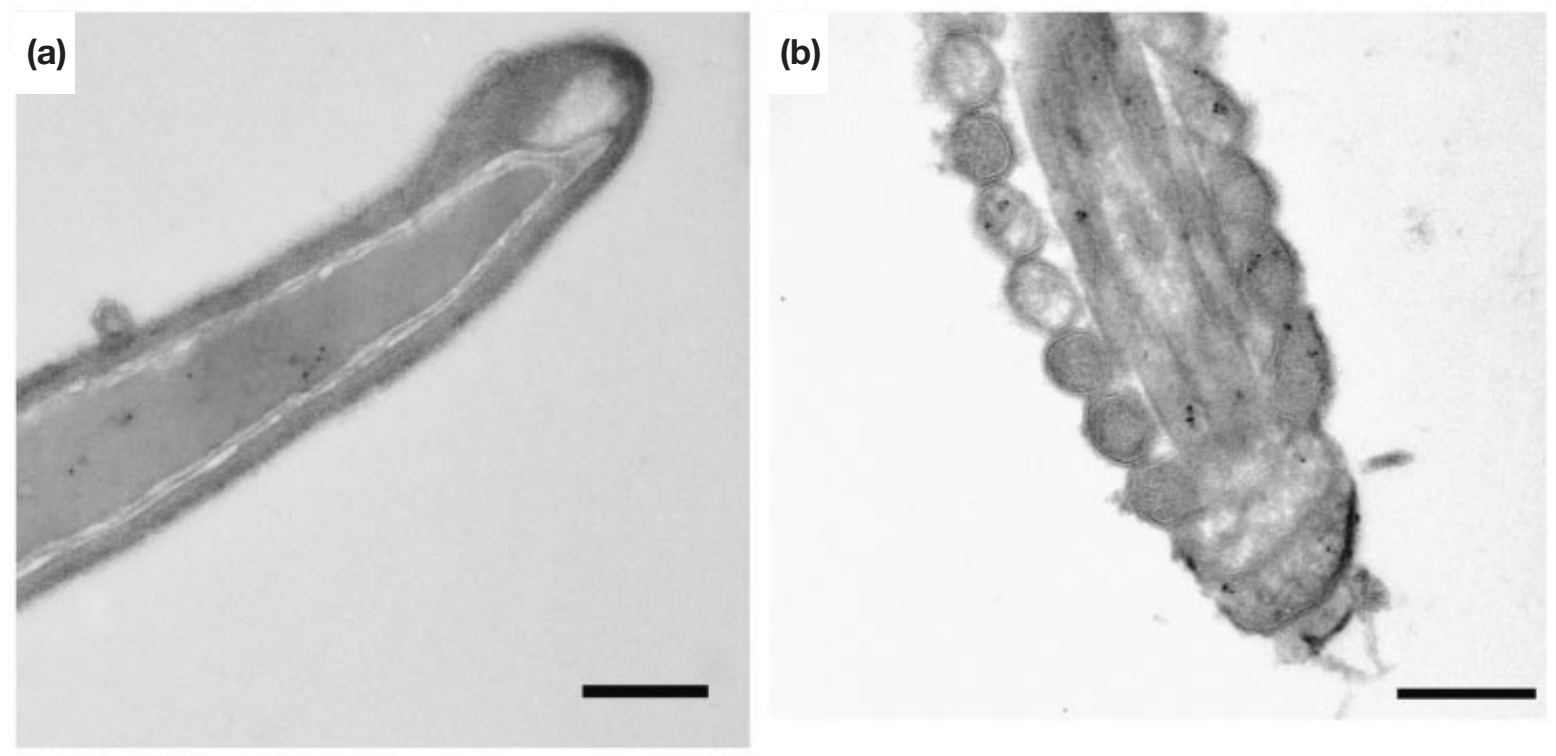

Fig. 8. Immunogold electron microscopy of glutamine-dependent carbamyl phosphate synthetase, aspartate transcarbamylase and dihydroorotase (CAD) in ram spermatozoa. Ram spermatozoa were fixed and sectioned. (a) Longitudinal section of the tip of the sperm head showing gold beads within the nucleus and (b) oblique section of mid-piece showing gold beads among the mitochondria. Scale bars represent $500 \mathrm{~nm}$.

cules were associated with an organelle that co-sediments with nuclei. In a recent biochemical analysis, the CAD protein has been identified within the nuclear matrix of mammalian cells, where it acts as an anchor protein through which adenovirus-directed replication is localized in discrete foci in the nucleus of the host cell (Angeletti and Engler, 1998). CAD and the adenovirus preterminal protein were found together in rings encircling the sites of active replication (shown by BrdU incorporation) in infected cells. CAD may have a similar role in the nucleus of uninfected cells, not directly connected with pyrimidine biosynthesis. It is difficult to imagine an active biosynthetic role for CAD in the nucleus of the mammalian spermatozoon.

In the present study, immunofluorescent microscopy of the BHK-21 cell line used by Chaparian and Evans (1988) confirmed the distribution of CAD in both the nucleus and cytoplasm. Similarly, in the ultra-thin sections used in electron microscopy, the labelled gold beads were seen in the nucleus and cytoplasm, where they clustered around the mitochondria. The ratio of gold beads found in the two compartments supports the idea that some CAD may always be present in the nucleus (see above).

In spermatozoa, substantial immunogold labelling of $\mathrm{CAD}$ is found throughout the nuclear matrix in the ultrathin sections, but immunofluorescent labelling is not found in the nucleus of intact spermatozoa. In this case, the lack of fluorescent label is probably caused by poor access, even in fixed cells, through the dense heterochromatin in the head, and does not indicate the absence of the protein.

Both immunofluorescent and immunogold labelling demonstrated the distribution of CAD in the mid-piece of spermatozoa, among the mitochondria. Fluorescent labelling also identifies this region as the location of UMPS and thus the association of these two proteins with the mitochondria has been confirmed.

Fluorescent labelling was also found in the thin cytoplasmic layer to the rear of the large acrosomal vesicle in spermatozoa, especially the intense anti-S2 signal observed in the equatorial region. CAD fluorescence is observed at the centrosome, and both CAD and UMPS are seen in the rear part of the head; this finding indicates that the two multi-enzyme proteins are not solely attached to the outside surface of the mitochondria in the mid-piece. A net-like distribution of fluorescence was observed in the fibroblast cytoplasm, indicating that these enzymes may be linked to a component of the cytoskeletal network. The intermediate filament protein, vimentin, is an important constituent of the network in the equatorial region of the spermatozoon (Curry and Watson, 1995). This protein has been shown to Copurify with nucleoside diphosphate kinase (Otero, 1997; Pinon et al., 1999) and with uridine phosphorylase (Russell et al., 2001).

It is an intriguing possibility that CAD may also associate with vimentin and with one or both of these other enzymes (nucleoside diphosphate kinase and uridine phosphorylase) if they are found in spermatozoa. As CAD has an UTPbinding site, nucleoside diphosphate kinase uses UDP as a substrate and uridine phosphorylase uses uridine, the combination of these enzymes may provide a sensitive means of detecting the external concentration of uridine. Uridine is a major component of seminal fluid (3-4 mmol $\mathrm{I}^{-1}$ : Ronquist et al., 1985) in which it may act to promote motility or as an 
anti-oxidant (M. Löffler, M. Hayek, H. A. Simmonds, L. D. Fairbanks and R. Henkel, unpublished). It is possible that as the spermatozoon travels up the reproductive tract and away from the bulk fluid, the loss of uridine may be detected and transmitted to the cytoskeleton, initiating changes in the shape of the cell or the location of the nucleus that are crucial to the acrosome reaction and fertilization.

There is no information on the expression of the pyrimidine biosynthetic enzymes during the stages of mammalian spermatogenesis to compare with the work in Drosophila (Porter et al., 1995; Yang et al., 1995). Whether the proteins are from a former developmental stage or whether they play a role during the process of capacitation (Harrison, 1996; Guraya, 2000; Travis et al., 2001) or fertilization remains to be elucidated. It should be noted that the entire spermatozoon, apart from the contents of the acrosome and its overlying membranes, enters the cytoplasm of the egg at fertilization (Ben-Yosef and Shaldi, 2001). The proteins of the nuclear matrix will accompany the DNA, and will be dispersed as the nucleus breaks up. Mitochondria and other organelles and proteins are ubiquitinated and destroyed soon after fertilization, but the centrioles remain (Schatten, 1994) possibly carrying a cargo of CAD along with the microtubules that are organized from the centrosome. There is evidence for the crucial role of some soluble proteins from spermatozoa (Swann, 1990; Fissore et al., 1998; Jones et al., 1998; Parrington et al., 1999) in permitting the changes that occur as the fertilized egg prepares for DNA replication and cell division. As there is no role for newly biosynthesized UMP in the spermatozoon, perhaps CAD and UMPS are carried into the egg to complete the pathway for pyrimidine biosynthesis after the male mitochondria are destroyed. However, the nuclear CAD may have an accessory role in the active replication of DNA; and cytoskeletal CAD may act as a monitor of external conditions (uridine concentration).

In summary, the results of the present study indicate that not only are CAD and UMPS found in spermatozoa, but also that they are located close to the mitochondria. These two proteins contain five enzyme activities between them and, with the mitochondrial enzyme $\mathrm{DHODH}$, they make up the six steps for biosynthesis of UMP. Thus, the enzymes for the complete biosynthetic pathway are physically associated in the cell. Immunoblot analysis confirmed that $\mathrm{DHODH}$ is found in the mitochondrial membrane, and that UMPS and CAD are located in the S100 extract (soluble portion) of mammalian spermatozoa. In addition, immunocytochemistry demonstrated that CAD and UMPS are found in the mid-piece of the spermatozoa, and that some CAD is also found in the nucleus of the fibroblasts and spermatozoa. It is also possible that CAD is connected with a cytoskeletal protein.

The authors thank Genus Breeding Ltd, Ruthin, Denbighshire for supply of bull semen, and GTC (South), PIC (UK) Ltd, Fyfield Wick, Abingdon for boar semen. The authors are grateful for the sample of antiserum from T. Traut, University of North Carolina, and for use of facilities provided by the Centre for High Resolution Imaging and Processing (CHIPS) at the University of Dundee. The authors gratefully acknowledge technical assistance from S. Fletcher and H. Hunt, Royal Veterinary College; J. James, CHIPS, Dundee; and J. Grulke, Marburg. JML was supported by a Research Leave Fellowship from the Wellcome Trust (059767/Z/99/Z) and by Tenovus Scotland. M. Löffler was supported by P.E. KempkesStiftung, Marburg. This work was supported by a Wellcome Trust grant to E. A. Carrey and P. F. Watson. The confocal microscope was purchased with an equipment grant from the Wellcome Trust.

\section{References}

Angeletti PC and Engler JA (1998) Adenovirus preterminal protein binds to the CAD enzyme at active sites of viral DNA replication on the nuclear matrix Journal of Virology 72 2896-2904

Ben-Yosef D and Shaldi R (2001) Oocyte activation: lessons from human infertility Trends in Molecular Medicine 7 163-169

Carrey EA and Hardie DG (1988) Mapping of catalytic domains and phosphorylation sites in the multifunctional pyrimidine-biosynthetic protein CAD European Journal of Biochemistry 171 583-588

Chaparian MG and Evans DR (1988) Intracellular location of the multidomain protein CAD in mammalian cells FASEB Journal 2 2982-2989

Chen J-J and Jones ME (1976) The cellular location of dihydroorotate dehydrogenase: relation to de novo biosynthesis of pyrimidines Archives of Biochemistry and Biophysics 176 82-90

Cheung C-W, Cohen NS and Raijman L (1989) Channelling of urea cycle intermediates in situ in permeabilized hepatocytes Journal of Biological Chemistry 264 4038-4044

Coleman PF, Suttle DP and Stark GR (1977) Purification from hamster cells of the multifunctional protein that initiates de novo synthesis of pyrimidine nucleotides Journal of Biological Chemistry 252 6379-6385

Conner T and Rawls J (1982) Analysis of the phenotypes exhibited by $r$-l mutants of D. melanogaster. Biochemical Genetics 20 607-619

Curry MR and Watson PF (1995) Sperm structure and function. In Gametes The Spermatozoon pp 45-69 Eds JG Grudzinskas and JL Yovich. Cambridge University Press, Cambridge

Deak D, Clifton AD, Lucocq JM and Alessi DA (1998) Mitogen- and stressactivated protein kinase-1 (MSK-1) a novel two-kinase domain enzyme that is directly activated by MAPK and SAPK2/p38 and which may mediate the activation of CREB EMBO Journal 17 4426-4441

Dietz C, Hinsch E and Löffler M (2000) Immunocytochemical detection of mitochondrial dihydroorotate dehydrogenase in human spermatozoa International Journal of Andrology 23 294-299

Fissore RA, Gordo AC and Wu H (1998) Activation of development in mammals: is there a role for sperm cytoplasmic factor? Theriogenology 49 43-52

Floyd EE and Jones ME (1982) Isolation and characterization of the orotidine 5 '-monophosphate decarboxylase domain of the multifunctional protein uridine 5'-monophosphate synthase Journal of Biological Chemistry 260 9443-9451

Guraya SS (2000) Cellular and molecular biology of capacitation and acrosome reaction in spermatozoa International Reviews in Cytology $1991-64$

Guy HI and Evans DR (1994) Cloning and expression of the mammalian multifunctional protein CAD in Escherichia coli. Journal of Biological Chemistry 26923 808-23 816

Han B-D, Livingstone LR, Pasek DA, Yablonski MJ and Jones ME (1995) Human uridine monophosphate synthase: baculovirus expression, immuno-affinity column purification and characterisation of the acetylated amino terminus Biochemistry 3410 835-10 843

Harlow E and Lane D (1988) Immunoaffinity purification of antibodies. In Antibodies: A Laboratory Manual pp 313-315. Cold Spring Harbor Laboratory, Cold Spring Harbour

Harrison RAP (1996) Capacitation mechanisms, and the role of capacitation as seen in eutherian mammals Reproduction, Fertilisation and Development 8 581-594 
Irvine HS, Shaw SM, Paton A and Carrey EA (1997) A reciprocal allosteric mechanism for efficient transfer of labile intermediates between active sites in CAD, the mammalian pyrimidine-biosynthetic multienzyme polypeptide European Journal of Biochemistry 247 1063-1073

Jones KT, Cruttwell C, Parrington J and Swann K (1998) A mammalian sperm cytosolic phospholipase $\mathrm{C}$ activity generates inositol trisphosphate and causes $\mathrm{Ca}^{2+}$ release in sea urchin egg homogenates FEBS Letters 437 297-300

Kempe TD, Swyryd EA, Bruist M and Stark GR (1976) Stable mutants of mammalian cells that overproduce the first three enzymes of pyrimidine nucleotide biosynthesis Cel/ 9 541-550

Lämmli UK (1970) Cleavage of structural proteins during the assembly of the head of bacteriophage T4 Nature 227 680-685

Löffler M, Becker C, Wegerle E and Schuster G (1996) Catalytic enzyme histochemistry and biochemical analysis of dihydroorotate dehydrogenase/ oxidase and succinate dehydrogenase in mammalian tissues, cells and mitochondria Histochemistry and Cell Biology 105 119-128

Lucocq JM (1992) Particulate markers for immunoelectron microscopy. In Fine Structure Immunocytochemistry pp 279-302 Ed. G Griffiths. Springer-Verlag, Berlin

Lucocq JM (1994) Quantitation of gold labelling and antigens in immunolabelled ultrathin sections Journal of Anatomy 184 1-13

Nørby S (1970) A specific nutritional requirement for pyrimidines in rudimentary mutants of D. melanogaster. Hereditas 66 205-214

Otero A deS (1997) Copurification of vimentin, energy metabolism enzymes, and a MER5 homolog with nucleoside diphosphate kinase. Identification of tissue-specific interactions Journal of Biological Chemistry 27214 690-14 694

Parrington J, Jones KT, Lai FA and Swann K (1999) The soluble sperm factor that causes $\mathrm{Ca}^{2+}$ release from sea-urchin egg homogenates also triggers $\mathrm{Ca}^{2+}$ oscillations after injection into mouse egg Biochemical Journal 341 $1-4$

Pinon VPB, Millot G, Munier A, Vassy J, Linares-Cruz G, Capeau J and Lacombe ML (1999) Cytoskeletal association of the A and B nucleoside diphosphate kinases of interphasic but not mitotic human carcinoma cell lines: specific nuclear localisation of the B subunit Experimental Cell Research 246 355-367

Porter L, Yang L and Rawls J (1995) Expression of de novo pyrimidine biosynthesis genes during spermatogenesis in $D$. melanogaster. Advances in Experimental Medicine and Biology 370 567-574

Rawls J, Knecht W, Diekert K, Lill R and Löffler M (2000) Requirements for the mitochondrial import and localisation of dihydroorotate dehydrogenase European Journal of Biochemistry 267 2079-2087

Ronquist G, Stegmayr B and Niklasson F (1985) Sperm motility and interactions among seminal uridine, xanthine, urate and ATPase in fertile and infertile men Archives of Andrology 15 21-27

Russell RL, Cao D, Zhang D, Handschumaker RE and Pizzorno G (2001) Uridine phosphorylase association with vimentin. Intracellular distribution and localisation Journal of Biological Chemistry $\mathbf{2 7 6}$ 13 302-13 307

Schatten G (1994) The centrosome and its mode of inheritance: the reduction of the centrosome during gametogenesis and its restoration during fertilisation Developmental Biology 165 299-335

Scully JL and Evans DR (1991) Comparative modelling of mammalian aspartate transcarbamylase Proteins: Structure, Function and Genetics 9 191-206

Shaw SM and Carrey EA (1992) Regulation of the mammalian carbamoylphosphate synthetase II by effectors and phosphorylation European Journal of Biochemistry 207 957-965

Suttle DP, Bugg BY, Winkler JK and Kanalas JJ (1988) Molecular cloning and nucleotide sequence for the complete coding region of human UMP synthase Proceedings National Academy of Sciences USA 85 1754-1758

Swann K (1990) A cytosolic sperm factor stimulates repetitive calcium increases and mimics fertilisation in hamster eggs Development $\mathbf{1 1 0}$ 1295-1302

Travis AJ, Foster JA, Rosenbaum NA, Visconti PE, Gerton GL, Kopf GS and Moss SB (1998) Targeting of a germ cell-specific type 1 hexokinase lacking a porin-binding domain to the mitochondria as well as to the head and fibrous sheath of murine spermatozoa Molecular Biology of the Cell $9263-276$

Travis AJ, Jorgez CJ, Merdiushev T, Jones BH, Dess DM, Diaz-Cueto L, Storey BT, Kopf GS and Moss SB (2001) Functionalised relationships between capacitation-dependent cell signalling and compartmentalised metabolic pathways in murine spermatozoa Journal of Biological Chemistry 276 7630-7636

Watford M (1991) The urea cycle: a two-compartment system Essays in Biochemistry 26 49-58 Ed. KF Tipton. Portland Press, London

Watson PF (1975) Use of a Giemsa stain to detect changes in acrosomes of frozen ram spermatozoa Veterinary Record 97 12-15

Yang J, Porter L and Rawls J (1995) Expression of the dihydroorotate dehydrogenase gene, dhod, during spermatogenesis in D. melanogaster. Molecular and General Genetics 246 334-341

Received 7 November 2001.

First decision 4 January 2002.

Revised manuscript received 1 February 2002.

Accepted 1 February 2002. 